RESEARCH PAPER RP783

Part of Journal of Research of the National Bureau of Standards, Volume 14, April 1935

\title{
ARC SPECTRUM OF COPPER IN THE INFRARED
}

\author{
By C. C. Kiess \\ ABSTRACT
}

A survey of the arc spectrum of copper out to the limit attainable photographically in the infrared has yielded about 30 new lines. All, except one, are accounted for as combinations between previously known terms of $\mathrm{Cu}$.

\section{INTRODUCTION}

The new types of photographic plates that the Eastman Kodak Co. ${ }^{1}$ has introduced, in recent years, have made it possible to record infrared spectra out to $12000 \mathrm{~A}$, and even somewhat beyond. These plates have been extensively used in the spectroscopy laboratory of the National Bureau of Standards to make systematic surveys of the near infrared spectra of most of the chemical elements. For some of the elements, results have already been published in several papers, ${ }^{2}$ to which reference should be made for a description of the apparatus and methods employed in these investigations. It is the purpose of this paper to present the infrared wave lengths that have been measured in the arc spectrum of copper.

The radiometric survey of the infrared are spectrum of copper, made in 1910 by Randall, ${ }^{3}$ revealed only six lines between 7000 and $30000 \mathrm{~A}$. Two of these form the intense doublet at 7933 and $8092 \mathrm{~A}$ which, subsequently, have had their wave lengths accurately determined from photographic observations. ${ }^{4}$ The other four lines lie between 16000 and $18000 \mathrm{~A}$, and are still beyond the reach of photographic methods. The lines longer than $8100 \mathrm{~A}$ observed in the copper arc by Meggers, are, with one exception, mostly attributable to the atmospheric gases, nitrogen and oxygen, which are excited when an electric arc passes between metallic electrodes in air.

The existence of lines in the infrared arc spectrum of copper may be predicted from the terms of $\mathrm{Cu}$ I given by Shenstone, ${ }^{5}$ who has made a practically complete analysis of the spectrum. In this analysis it is shown that nearly all the observed lines are accounted for as combinations between the doublet and quartet terms required by atomic theory. These terms arise from the addition of $s, p, d, \cdots$, electrons to the electron configurations $d^{10}$ and $d^{9} s$, which characterize the low and

\footnotetext{
1 Mees, J.Opt.Soc.Am. 22, 204 (1932).

2 BS Research Papers RP473, RP558, and RP624.

3 Randall, Astrophys. J. 348 (1911).

4 Eder, Sitz.Ber.Akad. Wiss. Wien IIa 124, 110 (1915). Meggers, BS §ci.Pap. 14, 385 (1918). Burns and Walters, Pub. Allegheny Observatory 8, 34 (1930).

5 Phys. Rev. 28, 449 (1926).
} 
metastable energy states of the singly ionized atom. It is of interest to note that most of the intense, sharp lines of the copper arc involve the doublet terms of the $d^{10}$ configuration, whereas all but a few of the numerous hazy and diffuse lines involve the doublet and quartet terms of the $d^{9} s$ configuration.

TABLE 1.-New lines in arc spectrum of $\mathrm{Cu}$

\begin{tabular}{|c|c|c|c|}
\hline$\lambda_{\mathrm{alr}} \mathrm{A}$ & $\begin{array}{l}\text { Intensity and } \\
\text { notes }\end{array}$ & $\begin{array}{l}\text { Wave number } \\
\text { (vac.) }\end{array}$ & Term combination \\
\hline $\begin{array}{l}11118.2 \\
10883.3 \\
10771.7 \\
10179.2 \\
10172.00\end{array}$ & $\begin{array}{l}1 h \\
1 \\
2 H \\
1 \\
20\end{array}$ & $\begin{array}{l}\text { 8991. } 8 \\
9185.8 \\
9281.0 \\
9821.2 \\
9828.23\end{array}$ & $\begin{array}{c}m 4 p{ }^{4} \mathrm{P}_{01 / 3}^{\circ} k 4 d d^{2} \mathrm{D}_{11 / 2} \\
k 5 p{ }^{2} \mathrm{P}_{11 / 2}^{\circ} k 8 s{ }^{2} \mathrm{~S}_{01 / 2} \\
n 4 p{ }^{2} \mathrm{D}_{11 / 2}^{\circ} n 5 s^{2} \mathrm{D}_{11 / 2} \\
m 4 p{ }^{4} \mathrm{P}_{11 / 2}^{\circ} k 4 d^{2}{ }^{2} \mathrm{D}_{11 / 2} \\
m 4 p{ }^{4} \mathrm{P}_{11 / 2}^{\circ} k 4 d^{2}{ }^{2} \mathrm{D}_{21 / 2}\end{array}$ \\
\hline $\begin{array}{c}10146.78 \\
10124.5 \\
9739.6 \\
9688.5 \\
9530.3\end{array}$ & $\begin{array}{r}50 b \\
5 H \\
4 H \\
2 H \\
10 H\end{array}$ & $\begin{array}{l}9852.64 \\
9874.3 \\
10264.6 \\
10318.7 \\
10490.0\end{array}$ & $\begin{array}{l}n 4 p{ }^{2} \mathrm{~F}_{21 / 2}^{\circ}-n 5 s{ }^{2} \mathrm{D}_{11 / 2} \\
k 6 p{ }^{2} \mathrm{P}_{11 / 2}^{\circ}-m 5 s{ }^{2} \mathrm{D}_{21 / 2} \\
k 5 p{ }^{2} \mathrm{P}_{11 / 2}^{\circ}-k 9 s{ }^{2} \mathrm{~S}_{01 / 2} \\
n 4 p{ }^{2} \mathrm{D}_{21 / 2}^{\circ}-n 5 s{ }^{2} \mathrm{D}_{21 / 2}\end{array}$ \\
\hline $\begin{array}{l}9472 . .^{4} \\
9263.0^{a} \\
9256.8^{-} \\
9213.5 \\
8996.2\end{array}$ & $\begin{array}{l}2 H \\
2 b \\
1 H \\
2 H \\
8 H\end{array}$ & $\begin{array}{l}10554.1 \\
10792.7 \\
10799.9 \\
10850.7 \\
11112.7\end{array}$ & 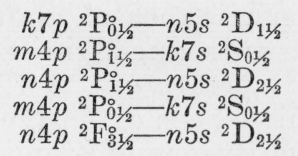 \\
\hline $\begin{array}{l}8831.3 \\
8584.0 \\
8408.15 \\
8006.21 \\
7000.0\end{array}$ & $\begin{array}{c}1 b \\
5 b \\
10 b \\
4 \\
1 h\end{array}$ & $\begin{array}{l}11320.3 \\
11646.4 \\
11889.96 \\
12486.87 \\
14281.8\end{array}$ & $\begin{array}{r}n 4 p{ }^{2} \mathrm{D}_{21 / 2}{ }^{2}-n 5 s^{2} \mathrm{D}_{11 / 2} \\
k 5 s{ }^{2} \mathrm{~S}_{01 / 2}-k 6 p{ }^{2} \mathrm{P}_{11 / 2}^{\circ} \\
k 5 s{ }^{2} \mathrm{~S}_{01 / 2}-k 6 p{ }^{2} \mathrm{P}_{01 / 2}^{\circ} \\
n 4 p{ }^{2} \mathrm{D}_{11 / 2}^{\circ}-m 4 d d^{4} \mathrm{P}_{21 / 2} \\
k 5 s^{2} \mathrm{~S}_{01 / 2}-k 7 p{ }^{2} \mathrm{P}_{01 / 2}^{\circ}\end{array}$ \\
\hline $\begin{array}{l}6968.34 \\
6634.7 \\
6433.35 \\
6373.3 \\
6165.7\end{array}$ & $\begin{array}{l}1 b \\
1 h \\
1 \\
1 \\
1 h\end{array}$ & $\begin{array}{l}14346.67 \\
15068.0 \\
15539.72 \\
15686.1 \\
16214.3\end{array}$ & $\begin{array}{l}n 4 p{ }^{2} \mathrm{D}_{21 / 2}^{\circ}-m 4 d d^{4} \mathrm{~S}_{11 / 2} \\
n 4 p{ }^{2} \mathrm{~F}_{31 / 2}^{\circ}-m 4 d^{2}{ }^{2} \mathrm{D}_{21 / 2} \\
n 4 p{ }^{2} \mathrm{P}_{11 / 2}^{\circ}-m 4 d d^{4} \mathrm{P}_{01 / 2} \\
k 7 p{ }^{2} \mathrm{P}_{01 / 2}^{\circ}-m 4 d^{2}{ }^{2} \mathrm{~S}_{01 / 2} \\
k 6 p{ }^{2} \mathrm{P}_{11 / 2}^{\circ}-m 4 d d^{4} \mathrm{~S}_{11 / 2}\end{array}$ \\
\hline $\begin{array}{l}5727.9 \\
5646.6 \\
5629.2\end{array}$ & $\begin{array}{l}2 h, l \\
1 h \\
1 H\end{array}$ & $\begin{array}{l}17453.6 \\
17704.9 \\
17759.6\end{array}$ & $\begin{array}{c}n 4 p{ }^{2} \mathrm{~F}_{21 / 2}^{\circ}-n 4 d^{2}{ }^{2} \mathrm{~F}_{31 / 2} \\
m 4 p{ }^{2} \mathrm{P}_{11 / 2}^{\circ}-m 5 s^{4} \mathrm{D}_{11 / 2} \\
k 5 p{ }^{2} \mathrm{P}_{11 / 2}^{\circ}-n 5 s^{2} \mathrm{D}_{21 / 2}^{\circ}\end{array}$ \\
\hline
\end{tabular}

a Blended with 9262.8 of oxygen.

Note. $k=3 d^{10}\left({ }^{1} \mathrm{~S}\right) ; \quad m=3 d^{9} 4 s\left({ }^{3} \mathrm{D}\right) ; n=3 d^{94} s\left({ }^{1} \mathrm{D}\right)$.

\section{RESULTS}

The new wave lengths for copper are given in table 1 and represent the average of two to eight observations, except for a few lines, observed on only one plate. The spectrograms, from which they were derived, were taken according to the experimental procedure described in the papers cited above, and required exposures of 2 and 3 hours. Most of the lines are diffuse and very hazy, which is indicated by the symbols $h$ and $H$ following the intensity estimate. A few of the lines appear to be widened, without, however, showing the haziness presented by the others. This characteristic is denoted by $b$. The letter $l$ indicates an unsymmetrical shading of the line toward longer wave lengths. 
All but one of the new lines are accounted for as combinations between the terms given by Shenstone. These terms, however, are not designated by the symbols originally assigned by him, but by those conforming to present usage, given by Bacher and Goudsmit. ${ }^{6}$ It is of interest to note that nearly all the new hazy lines also involve terms belonging to configurations containing the $d^{9} s$ electrons.

In addition to the new infrared lines, table 1 also contains some lines of $\mathrm{Cu}$ I which have been measured at various times at the National Bureau of Standards, during the spectroscopic examination of materials for which copper rods were used as supporting electrodes. These lines, which do not appear in any of the published lists of wave lengths are all satisfactorily accounted for by Shenstone's terms, and are, therefore, presented at this time to extend the description of $\mathrm{Cu}$ I.

WASHington, January 23, 1935.

${ }^{6}$ Bacher and Goudsmit, Atomic Energy States, page 175 (McGraw-Hill Book Co., New York, 1932). 